\title{
Article
}

\section{Healthy living champions network: An opportunity for community pharmacy's sustained participation in tackling local health inequalities}

Rutter, Paul, Nazar, Zachariah, Portlock, Jane and Brown, David Available at http://clok.uclan.ac.uk/14201/

Rutter, Paul ORCID: 0000-0003-4106-1515, Nazar, Zachariah, Portlock, Jane and Brown, David (2016) Healthy living champions network: An opportunity for community pharmacy's sustained participation in tackling local health inequalities. Research in Social and Administrative Pharmacy, 12 (6). pp. 1010-1015. ISSN 1551-7411

It is advisable to refer to the publisher's version if you intend to cite from the work. http://dx.doi.org/10.1016/j.sapharm.2015.12.010

For more information about UCLan's research in this area go to http://www.uclan.ac.uk/researchgroups/ and search for <name of research Group>.

For information about Research generally at UCLan please go to http://www.uclan.ac.uk/research/

All outputs in CLoK are protected by Intellectual Property Rights law, including Copyright law. Copyright, IPR and Moral Rights for the works on this site are retained by the individual authors and/or other copyright owners. Terms and conditions for use of this material are defined in the policies page. 


\section{Accepted Manuscript}

Healthy Living Champions network: An opportunity for community pharmacy's

sustained participation in tackling local health inequalities

Zachariah Nazar, Jane Portlock, Paul Rutter, David Brown

PII: S1551-7411(15)00284-3

DOI: $\quad$ 10.1016/j.sapharm.2015.12.010

Reference: RSAP 693

To appear in: Research in Social \& Administrative Pharmacy

Received Date: 27 August 2015

Revised Date: 20 December 2015

Accepted Date: 20 December 2015

Please cite this article as: Nazar Z, Portlock J, Rutter P, Brown D, Healthy Living Champions network: An opportunity for community pharmacy's sustained participation in tackling local health inequalities, Research in Social \& Administrative Pharmacy (2016), doi: 10.1016/j.sapharm.2015.12.010.

This is a PDF file of an unedited manuscript that has been accepted for publication. As a service to our customers we are providing this early version of the manuscript. The manuscript will undergo copyediting, typesetting, and review of the resulting proof before it is published in its final form. Please note that during the production process errors may be discovered which could affect the content, and all legal disclaimers that apply to the journal pertain. 
Healthy Living Champions network: An opportunity for community pharmacy's sustained participation in addressing health inequalities

\author{
Zachariah Nazar ${ }^{1}$, Jane Portlock ${ }^{1}$, Paul Rutter $^{2}$, David Brown ${ }^{1}$ \\ ${ }^{1}$ School of Pharmacy \& Biomedical Science, University of Portsmouth, PO1 2DT. UK \\ ${ }^{2}$ School of Pharmacy, University of Central Lancashire, PR1 2HE. UK
}

Conflicts of interest: none

\title{
Corresponding Author:
}

Zachariah Nazar

School of Pharmacy \& Biomedical Science,

University of Portsmouth,

St. Michael's Building, White Swan Rd,

Portsmouth, Hampshire,

PO1 2DT, UK

Tel : 02392843337

E-mail: Zachariah.nazar@port.ac.uk 
Article Synopsis:

This study employed focus groups to explore Healthy Living Champions' (HLC) opinions on the networking opportunities available and their contribution to sustained participation in the Healthy Living Pharmacy initiative.

The outcomes have added to the existing body of evidence that HLCs are motivated to develop their role in delivering pharmacy services and are key facilitators in the continued success of the HLP project.

This research has identified the important contribution of HLC network meetings in providing HLCs with professional development, networking opportunities and continued enthusiasm. Furthermore this study offers recommendations to develop and sustain the HLC network. 


\section{Abstract}

Background: Evaluations recognise healthy living champions (HLCs) as key contributors to the Health Living Pharmacy (HLP) project's success; the project has served to reduce pressure on family doctor services and clients who would have otherwise not sought professional advice have accessed HLP services.

Objectives: To investigate the impact of innovative networking opportunities in supporting HLCs to function within their role and to explore the network's potential in promoting sustained HLP participation.

Method: Twenty of Portsmouth's (England) HLCs $(n=33)$ agreed to participate in focus groups. Transcripts were subjected to interpretative phenomenological analysis guided by grounded theory. The transcripts were read repeatedly; recurrent themes were identified and coded manually and consensus was reached by discussion within the research team.

Findings: Network meetings provide HLCs with professional development, networking opportunities and continued encouragement. Recommendations to develop and sustain the network included the formation of a group committee and establishing of a communication facility accessible between meetings.

Conclusion: The successful Portsmouth HLP project informed the design of UK HLP projects. The current focus is to build a successful strategy to sustain the positive outcomes, building on the recognised enablers. This study contributes further lessons learnt to guide health commissioners and service implementers to best support staff development, involvement and motivation through innovative practice.

Key words: Healthy people programs; healthy living pharmacy; community pharmacy services; community health network; health promotion 


\section{Healthy Living Champions network: An opportunity for community pharmacy's sustained participation in tackling local health inequalities}

\section{Introduction}

Within global health policy, self-care is becoming an increasingly prominent element of patient care ${ }^{1-3}$. Community pharmacy offers a number of benefits as a setting for delivering self-care activities and advice. With extended opening hours and no appointment needed for advice, community pharmacy can be more accessible than other settings ${ }^{4}$. Research has recognised that the public trusts advice received from community pharmacies ${ }^{5}$. A review of evidence has confirmed the potential of pharmacy in the area of delivering public health initiatives, and suggests that pharmacy teams can make a positive contribution to public health ${ }^{6}$.

The White Paper, Pharmacy in England: Building on strengths, delivering the future $(2008)^{7}$ identified the potential for establishing a role for community pharmacies within the public health service sector across England. Recommendations were made to increase pharmacy's contribution to promoting better health, prevention and early detection of disease and managing patients with long-term conditions.

The Healthy Living Pharmacy (HLP) initiative is a Department of Health (DoH) commissioned project designed to quality-assure the delivery of health and well-being services that address local health inequalities ${ }^{8}$.

The project, piloted in Portsmouth in 2010 and rolled out nationally in 2011, appears to have made a positive impact on community pharmacy services ${ }^{9}$. It has produced a strong community of participating pharmacies and clients have benefitted from the services provided $^{10,11}$. Table 1 illustrates key benefits to pharmacy contractors who adopted the HLP model.

Table 1:UK HLP evaluation of pharmacy contractors $(n=153)^{10}$

$33 \%$ Experienced higher prescription volumes

$43 \%$ Reported a rise in income

$61 \%$ Experienced increased demand for services

$80 \%$ Found staff were more productive

The national evaluation identified that $20 \%$ of individuals $(n=1034)$ using HLP services would not have accessed services elsewhere, thus facing the risk of deterioration in their health, and $60 \%$ of individuals would have otherwise accessed their family doctor, thus further burdening this already overwhelmed resource ${ }^{12}$. The evaluation also recognised, in different demographics and geographies, there is a consistent performance across different services delivered by HLPs, suggesting that the HLP concept can be replicated in other areas.

An extensive body of evidence demonstrates the improved health outcomes from community pharmacy initiatives ${ }^{6,9}$. However, research has indicated that although the diversifying role of community pharmacy from traditional dispensing activities to greater involvement in health improvement is largely accepted, and the importance of providing health and well-being services is understood, the role is still considered secondary to medicine related roles. However despite some initial success, many pharmacists view public health activities as less 
important than traditional roles and cite lack of time and confidence as barriers to further expansion of service provision ${ }^{5,6,13}$.

It has since been recognised that employing the appropriate skill mix in community pharmacy is a key enabler in enhancing pharmaceutical care by making better use of the knowledge and aptitude of pharmacy support staff and pharmacists ${ }^{14}$. Effective use of skill mix in upskilling support staff and education provision has resulted in improved efficiency, sustained service involvement and freeing up pharmacist's time ${ }^{15}$.

The HLP framework recognised the benefits of skill mix and considered the integral contribution pharmacy support staff could have in service delivery ${ }^{10,11}$. To deliver the HLP concept there was a criterion for a non-pharmacist member of staff to undergo further training and become a healthy living champion (HLC). The role of the HLC includes proactively engaging with the public, understanding the local health and well-being services available, establishing and maintaining a health promotion zone and delivering health and well-being services within the pharmacy.

Table 2 summarises some of the training available for HLCs.

\section{Table 2: Training for HLCs}

There are many national and local organisations that provide accredited HLC courses including the core Royal Society for Public Health's(RSPH) Understanding Health Improvement Level 2 qualification ${ }^{16}$

This course consists of four modules followed by a Multiple Choice Question assessment:

- Inequalities in health

- How effective communication can support health messages

- Importance of promoting improvements in health and well-being

- Impact of behaviour change on health and well-being

In addition the RSPH offers other qualifications to further develop the skills and knowledge of a Healthy Living Champion:

- Level 2 Award in Applied Health Improvement

- Level 2 Award in Encouraging a Healthy Weight and Healthy Eating

- Level 2 Award in Encouraging Physical Activity

- Level 2 Award in Health Promotion (General Health and Wellbeing)

- Level 2 Award in Health Promotion (Oral Health)

- Level 2 Award in Supporting Smoking Cessation

- Level 2 Award in Understanding Alcohol Misuse

- Level 2 Award in Understanding Behaviour Change

- Level 2 Award in Understanding the Delivery of an NHS Health Check

Research investigating HLP success revealed the key role HLCs played in motivating staff, networking and collaborating with local pharmacy teams in community outreach projects, and supporting continued engagement with the HLP project ${ }^{11}$. Furthermore, research has identified that pharmacy staff trained as HLCs embraced the role and saw personal and patient benefit in delivering pharmacy public health services ${ }^{17}$. 
In Portsmouth, a 'pharmacy community' was created ${ }^{11}$, whereby the HLCs formed a networking group and met periodically. HLCs reported that these meetings acted as a source of motivation to engage with HLP activities ${ }^{11}$. The local commissioner, therefore, continued to facilitate and fund networking meetings. The aim of this was to sustain the enthusiasm around HLP activities and to ensure the key role HLCs contribute in delivering HLP engagement, was supported with education and professional development.

Although the key enablers for HLP delivery have been recognised in the literature, ${ }^{10,18,19}$ research to identify the facilitators for continued participation has yet to be conducted. This study aimed to investigate the impact of innovative networking opportunities in supporting HLCs to function within their role and to explore the network's potential in promoting sustained participation in the HLP initiative.

\section{Methods}

All HLCs working in each of Portsmouth's community pharmacies that were operating as HLPs $(n=33)$ were invited to take part in focus groups held in a local community centre. Two focus groups, each of 10 volunteering participants were arranged to allow for optimal group size $^{20}$. Care was taken in assigning individuals to each group to support heterogeneous grouping to avoid persons who work together being in the same group and the number of persons working for multiple-group pharmacies and independently owned pharmacies were equally divided.

Prior to the focus group, questions were pre-tested and reviewed for face validity with 5 staff employed at a single community pharmacy, to ensure that the wording would be understood by all potential participants. The review determined that no changes to the wording of the questions were required.

The focus group questions are outlined in Table 3.

\section{Table 3: Focus group questions}

Why do you attend the HLC meetings?

Can you describe the impact brought about by attending these meetings?

What are your thoughts on how the meetings are delivered?

How can these meetings be improved?

Are there aspects of the meetings you consider beneficial to your role?

Is there anything you would like to see changed to the HLP meetings?

What can be done to help sustain activity in the HLP project?

The interview questions were designed to enable the participants to express their own opinions and experiences of the HLC meetings. To capture non-attenders and to consolidate the views expressed by those that did attend, a semi-structured questionnaire based on themes generated through the focus groups was circulated to all HLCs.

Two trained assistants were present at each focus group: one as the moderator and the other managed audio-recording and making field notes ${ }^{20}$. 
The discussions were transcribed verbatim by the researcher $(\mathrm{ZN})$ and checked by the trained assistants. Analysis was by way of interpretative phenomenological analysis guided by grounded theory ${ }^{21}$. The transcripts were read repeatedly; recurrent themes were identified and coded manually and consensus was reached by discussion between the researcher $(\mathrm{ZN})$ and the two trained assistants. These were validated by a member of the research team (DB).

This research received a favourable opinion from the Portsmouth NHS Local Research Ethics Committee as part of the wider evaluation of the HLP in Portsmouth.

\section{Results}

Twenty HLCs agreed to participate in the focus groups. Two focus groups, each of 10 participants were arranged. Each focus group lasted approximately 40 minutes. The themes from the first focus group re-emerged from the second focus group with similar emphasis and frequency, achieving saturation.

The semi-structured questionnaires confirmed the breadth of the themes and did not generate any further themes formulated in the focus groups.

Table 4 identifies the themes and sub-themes that emerged from the 2 focus groups.

Table 4: Themes and sub-themes to have emerged from the focus groups

\begin{tabular}{|c|c|}
\hline Theme & Sub-theme \\
\hline $\begin{array}{l}\text { Benefits of attending } \\
\text { the HLC meetings }\end{array}$ & $\begin{array}{l}\text { - An opportunity to network } \\
\text { - A source of motivation to engage in HLP activities } \\
\text { - A platform for discussions around health promotion } \\
\text { campaigns } \\
\text { - Sharing ideas of patient recruitment and service promotion } \\
\text { - Initiating relationships for collaborative projects in the local } \\
\text { - A senmunity } \\
\text { similar goals }\end{array}$ \\
\hline $\begin{array}{l}\text { Setup and content of } \\
\text { the HLC meetings }\end{array}$ & $\begin{array}{l}\text { - A central location and convenient timing are important } \\
\text { - A demonstration of good practice in delivering specific HLP } \\
\text { services is a valued inclusion } \\
\text { - Updates of specific pharmacies service activity and } \\
\text { success acts to motivate further service delivery } \\
\text { - Training delivered by practitioners involved in HLP services } \\
\text { help contextualise the HLC role }\end{array}$ \\
\hline Future developments & $\begin{array}{l}\text { - An advanced schedule of HLC meetings } \\
\text { - The formation of a group committee responsible for } \\
\text { administrative tasks and communications } \\
\text { - A facility to allow communications to continue in between } \\
\text { meetings }\end{array}$ \\
\hline
\end{tabular}

\section{Discussion}

The HLP initiative demonstrates an effective platform through which community pharmacy's role in delivering health and well-being services can be realised; this has been achieved 
through better utilisation of pharmacy staff ${ }^{15,22,23}$. Research has identified effective team working and staff motivation as key enablers and facilitators in supporting the HLP initiative $^{11,23}$. It would, therefore, seem unreasonable to consider implementation of the HLP project without considering the valuable role of HLCs and their contribution to sustained engagement in the project.

Early suggestions of strategies to facilitate continued engagement of HLCs are beginning to appear in local HLP evaluation documents ${ }^{18,19,24}$; however, this report is the first to analyse the impact of such a strategy. Portsmouth, being the pilot site for the HLP project, was the first location to identify the potentially significant contribution of HLCs in HLP engagement. The investigation of the HLC community described in this study provides a valuable insight into their value for other HLP projects around the UK and further afield. It also helps to inform a business development model in the wider commercial environment.

This study specifically identified the benefits for HLCs in attending networking meetings facilitated and funded by the local commissioner of the service. Firstly, HLCs were enthused and returned to their workplace feeling more motivated to continue in their role. Secondly, the meetings provided an opportunity for HLCs to share ideas and initiate collaboration for health promotional activities outside of the workplace. Thirdly, the training incorporated into the meetings enhanced the HLCs' understanding of their role in public health services.

These findings support published research demonstrating that HLPs lead to the creation of a 'pharmacy community', whereby working relationships are established through interactions between staff at joint training sessions and continued communications in between sessions $^{22}$. Furthermore, this study confirms research that has identified the role of the commissioner in supporting staff education and training to be important in HLP support ${ }^{22,23}$.

Similarly, it has been recognised in wider healthcare research, that communities working towards improving the health of specific groups of patients have found that they are more likely to be successful if they work collaboratively within their communities ${ }^{25}$.

It should be recognised that when a public funding agency ceases to remain involved in community projects, the effectiveness of the collaboration within a network may be diminished ${ }^{26}$. The relevance of this is significant, since the commissioner's role has been recognised to support the HLP initiative; however the dynamic nature of the National Health Service (NHS) commissioning environment means that continued involvement in the project is not guaranteed.

The HLCs claimed that the absence of a facility for disseminating meeting details and allowing communication in between meetings resulted in variable HLC attendance. This was identified as a barrier impeding the progress and success of the meetings. HLCs saw the formation of a committee to take on the leadership of the group in managing communications and administrative functions to mitigate and improve poor communication previously encountered.

Implementation of a communication tool, which serves the desired functions as mentioned by the HLCs and the formation of a group committee to undertake administrative functions are the next steps towards consolidating the sustainability of the HLP initiative through the motivation and contribution of HLCs. 
An evaluation of these enterprises, including qualitative feedback on the usability and perceived benefits of a communication tool; and also analysis on the impact on HLP delivery would then be necessary and provide valuable information for the future development and sustainability of HLP programs elsewhere.

\section{Conclusion}

The HLP project was introduced to improve patient outcomes by increasing pharmacy's contribution to promoting better health, prevention and early detection of disease and managing patients with long-term conditions. Evaluations of the project throughout the UK are consistent in that the project produces a strong community of participating pharmacies and clients have benefitted from the services provided. Furthermore, there is evidence that the project has served to reduce pressure on family doctor services and HLP services have been accessed by patients who would have otherwise not sought professional advice. The present study identified the important contribution of HLC network meetings in providing HLCs with professional development, networking opportunities and continued enthusiasm. It thus offers recommendations to develop and sustain the HLC network, through the formation of a group committee and establishing a robust communication facility accessible in between meetings. It also contributes lessons learnt to guide health commissioners and service implementers to best support staff development, involvement and motivation through innovative practice.

1. U. K. Parliament Department of Health. Healthy Lives, Healthy People: Our strategy for public health in England: TSO; 2010. (Available

at:)http://www.dh.gov.uk/en/Publicationsandstatistics/Publications/PublicationsPolicyAndG uidance/DH_121941. Accessed November $11^{\text {th }}, 2015$.

2. Australian Government: Dept H, Ageing. Building a 21st Century Primary Health Care System: Australia's First National Primary Health Care Strategy. 2010.

3. Scahill S, Harrison J, Carswell P, Shaw J. Health care policy and community pharmacy: implications for the New Zealand primary health care sector. NZ Med J. 2010;123:41-51.

4. Eades CE, Ferguson JS, O'Carroll RE. Public health in community pharmacy: a systematic review of pharmacist and consumer views. BMC Public Health. 2011;11:582.

5. Anderson C. Health promotion in community pharmacy: the UK situation. Pat Educ Counsel. 2000;39:285-291.

6. Anderson C, Blenkinsopp A, Armstrong M. Feedback from community pharmacy users on the contribution of community pharmacy to improving the public's health: a systematic review of the peer reviewed and non-peer reviewed literature 1990--2002. Health Expectations. 2004;7:191-202 112p.

7. U. K. Parliament Department of Health. Pharmacy in England: Building on Strengths Delivering the Future: TSO; 2008. (Available at:)www.dh.gov.uk/en/Publicationsandstatistics/Publications/PublicationsPolicyAndGuidanc e/DH_083815.Accessed November 11 $1^{\text {th }}, 2015$

8. National Pharmacy Association. Healthy Living Pharmacy Overview: St Albans: National Pharmacy Association. Available online at: http://www.npa.co.uk/Documents/HLP/HLP_overview_12; 2011. Accessed November $11^{\text {th }}$, 2015.

9. Brown D, Portlock J, Rutter P. Review of services provided by pharmacies that promote healthy living. Int J Clin Pharm. 2012;34:399-409. 
10. Duggan C, Evans D, Holden $M$, et al. Evaluation of the healthy living pharmacy pathfinder work programme 2011-2012. Healthy Living Pharmacy. 2013.

11. Brown D, Portlock J, Rutter P, Nazar Z. From community pharmacy to healthy living pharmacy: Positive early experiences from Portsmouth, England. Res Social Adm Pharm. 2014;10:72-87.

12. Dale J, Potter R, Owen $K$, Parsons N, Realpe A, Leach J. Retaining the general practitioner workforce in England: what matters to GPs? A cross-sectional study. BMC Family Practice. 2015;16:1-11.

13. Anderson C, Blenkinsopp A. Community pharmacy supply of emergency hormonal contraception: a structured literature review of international evidence. Human Reproduction. 2006;21:272-284.

14. Schafheutle El, Samuels T, Hassell K. Support staff in community pharmacy: Who are they and what do they want? Int J Pharm Pract. 2008;16:57-63.

15. Ferguson R. Skill mix in the pharmacy. Chemist \& Druggist. 2015;282:14-16 13p.

16. Royal Society for Public Health. Level 2 Award in Understanding Health Improvement. Web site https://www.rsph.org.uk/en/qualifications/qualifications.cfm?level=2 Updated 2015. Accessed November $11^{\text {th }}, 2015$.

17. Rutter P, Vryaparj G. Qualitative exploration of the views of healthy living champions from pharmacies in England. Int J Clin Pharm. 2015;37:27-30.

18. Langley CA, Bush J, Patel A. An Evaluation: The Implementation and Impact of Healthy Living Pharmacies within the Heart of Birmingham. 2014.

19. Mohan L, McNaughton R, Shucksmith J. An evaluation of the Tees healthy living pharmacy pilot scheme. Middlesborough: University of Teesside, Health and Social Care Institute. 2013.

20. Barbour R. Doing focus groups: Sage; 2008.

21. Smith JA. Beyond the divide between cognition and discourse: Using interpretative phenomenological analysis in health psychology. Psychology and Health. 1996;11:261-271.

22. Firth $\mathrm{H}$, Todd $\mathrm{A}$, Bambra $\mathrm{C}$. Benefits and barriers to the public health pharmacy: a qualitative exploration of providers' and commissioners' perceptions of the Healthy Living Pharmacy framework. Perspectives in public health. 2015:1757913915579457.

23. Donovan G, Paudyal V. England's Healthy Living Pharmacy (HLP) Initiative: Facilitating the Engagement of Pharmacy Support Staff in Public Health. Res Social Adm Pharm. 2015.

24. Ali L, An-Enbaree A, Aurangzeb M, Hussain N, Hussain S. Evaluation of the West Yorkshire Healthy Living Pharmacy Programme. 2014.

25. Satcher D. Our commitment to eliminate racial and ethnic health disparities. Yale J. Health Pol'y L. \& Ethics. 2001;1:1.

26. Rodríguez C, Langley A, Béland F, Denis J-L. Governance, power, and mandated collaboration in an interorganizational network. Administration \& Society. 2007;39:150-193. 
Healthy Living Champions network: An opportunity for community pharmacy's sustained participation in tackling health inequalities

Highlights:

- Attending network meetings motivates staff to deliver public health services

- Network meetings have served to initiate collaboration between local pharmacies

- A formal committee and designated responsibilities may sustain network meetings

- Introducing an online communication facility may enhance the network's benefit 